\title{
Une minorité et son guide spirituel : la communauté séfarade de Londres et le rabbin David Nieto (1701-1728)
}

A Minority and its Spiritual Guide: the Sephardic Jews of London and their

Rabbi, David Nieto (1701-1728)

\section{Sarah Mimran}

\section{OpenEdition}

Journals

Édition électronique

URL : http://journals.openedition.org/rfcb/671

DOI : 10.4000/rfcb.671

ISSN : 2429-4373

Éditeur

CRECIB - Centre de recherche et d'études en civilisation britannique

Édition imprimée

Date de publication : 15 octobre 2012

Pagination : $37-60$

ISBN : 2-911580-37-0

ISSN : 0248-9015

\section{Référence électronique}

Sarah Mimran, «Une minorité et son guide spirituel : la communauté séfarade de Londres et le rabbin David Nieto (1701-1728)», Revue Française de Civilisation Britannique [En ligne], XVII-2 | 2012, mis en ligne le 15 mars 2016, consulté le 30 avril 2019. URL : http://journals.openedition.org/rfcb/671 ; DOI : $10.4000 /$ rfcb.671

Ce document a été généré automatiquement le 30 avril 2019.

Revue française de civilisation britannique est mis à disposition selon les termes de la licence Creative Commons Attribution - Pas d'Utilisation Commerciale - Pas de Modification 4.0 International. 


\title{
Une minorité et son guide spirituel : la communauté séfarade de Londres et le rabbin David Nieto (1701-1728)
}

\author{
A Minority and its Spiritual Guide: the Sephardic Jews of London and their \\ Rabbi, David Nieto (1701-1728)
}

\author{
Sarah Mimran
}

1 Il avait vu le jour à Venise en 1654 et, à l'instar peut-être de l'illustre Maïmonide (1135-1204), il aspirait à devenir à la fois rabbin, philosophe et médecin. Le parcours académique s'annonçait laborieux pour le Juif de l'époque qu'il était, mais ni le courage, ni l'énergie et ni les capacités ne faisaient défaut à David Nieto. ${ }^{1}$ L'université de Padoue lui ouvrit ses portes, et il étudia parallèlement la théologie juive et le Talmud auprès des autorités rabbiniques locales. En 1687, la faculté décernait au jeune rabbin les diplômes de médecin et de philosophe et, moins d'une décennie plus tard, il était déjà célèbre à Livourne en tant que juge rabbinique, directeur de l'institut talmudique Réchit Hokhma (Les Prémisses de la Sagesse), professeur de médecine, astronome réputé, historien, théologien, poète, et il maîtrisait conjointement l'hébreu, le français, le grec, le latin, l'italien, le portugais et l'espagnol - l'anglais ne devant s'ajouter qu'ultérieurement à la liste $^{2}$.

2 Lorsqu'en 1701, le haham ${ }^{3}$ Solomon Judah Ayllon quitta la petite communauté juive de Londres pour rejoindre celle d'Amsterdam, le nom déjà célèbre de David Nieto jaillit spontanément sur toutes les lèvres; convaincus qu'il saurait les guider et redorer leur blason, les Séfarades anglais lui offrirent en toute confiance la présidence de leurs destinées spirituelles - à la condition toutefois qu'il se consacre pleinement à sa mission et délaisse ses activités médicales.

3 Mais qui étaient au juste ces Juifs « espagnols et portugais » auprès desquels s'engageait l'érudit livournais? Comment se présentait et s'organisait cette communauté juive, réadmise sur le sol britannique en 1656 , et donc plus jeune même que son nouveau haham ? Petit îlot d'apparence paisible, se développant à l'ombre protectrice d'une tolérance 
nouvelle, la minorité séfarade de Londres était, à l'aube du XVIII siècle, en pleine construction et en pleine croissance. Traditionnellement solidaire, férue de lettres et d'éducation, elle ne se départait toutefois pas encore d'une préhistoire troublante: en quête de son identité, elle luttait fougueusement pour affermir sa foi, en définir un contenu lumineux et univoque, et en tracer des contours clairs et distincts.

\section{Un îlot tranquille, une communauté diversifiée et en pleine croissance}

4 Lorsque David Nieto arriva à Londres au cours du dernier trimestre de l'année $1701^{4}$ accompagné de son épouse Sarah et de leurs trois fils, Moses, Pinhas et Isaac, les Juifs avaient déjà bâti les grandes structures de leur nouvelle société. L'affluence progressive d'immigrés ashkénazes - en provenance d'Europe centrale et orientale - ainsi que leur nouvelle importance numérique avaient généré une scission d'ordre pragmatique entre ces derniers et les Séfarades d'origine ; rendue nécessaire par la volonté de respecter et de perpétuer les us et coutumes liturgiques en vigueur dans chacun des deux groupes, la formation de la première congrégation ashkénaze s'était imposée dès 1690 autour d'une synagogue, puis d'un cimetière propres. Régulièrement en relation, évoluant côte à côte dans la capitale et fréquentant des synagogues voisines, les communautés ashkénaze et séfarade suivirent depuis un cheminement parallèle, qui n'excluait pas pour autant des points d'intersection, comme la naissance d'un organisme politique commun, the Jewish Board of Deputies, en 1760.

5 C'est le Mahamad ou Conseil de la congrégation séfarade composé de cinq membres laïcs élus parmi les affiliés privilégiés de la communauté, qui avait fait appel à David Nieto au départ du précédent haham. La proposition était signée par Isaac Israel Correa, Isaac Lopes Pereira, Abraham Vaes Martines, Isaac Israel Henriques et Moses Franciatrésorier général ${ }^{5}$. Dès 1663 , le Conseil s'était chargé de compiler les statuts de la jeune collectivité et de rédiger les quarante-deux articles, inspirés des modèles d'Amsterdam et de Venise, qui établissaient sa constitution; la langue d'origine était l'espagnol puis, jusqu'en 1819, les retouches et suppléments se faisaient en portugais, langue vernaculaire des Séfarades de Londres - qui ne faisaient à l'époque usage de l'anglais que lors des échanges commerciaux ou des contacts avec leurs concitoyens non-Juifs. Le Conseil disposait d'un large éventail d'attributions: il déterminait les limites de l'autorité du rabbin, accordait les divorces, établissait le montant de la participation financière des résidents et des visiteurs sur la base de leurs revenus ou des transactions commerciales effectuées, fixait l'aide octroyée aux pauvres et pourvoyait à leur éducation, réglait les différends juridiques au sein de la communauté, et veillait au respect de toutes ces mesures ${ }^{6}$. Ce document législatif souligne l'extrême prudence des premiers responsables communautaires, soucieux de préserver la bonne réputation de la congrégation et de prévenir à tout prix un nouvel épisode douloureux d'expulsion, et leur volonté de pratiquer librement les préceptes du judaïsme sans perturber ou risquer d'offenser, par l'acte ou la parole, ceux qui les accueillaient avec bienveillance. Le Conseil se réservait donc un droit de censure : afin que l'un de ses membres ne porte préjudice à l'ensemble du groupe, une autorisation préalable était exigée avant toute publication. Pour éviter encore tout dérapage verbal ou scandale, les discussions théologiques avec des non-Juifs étaient rigoureusement interdites ${ }^{7}$. Si toutes ces mesures étaient théoriquement valables à l'arrivée du nouveau haham en 1701, il apparaît toutefois que le Conseil ait voué une 
grande confiance à David Nieto: ce dernier entretenait de nombreux échanges épistolaires avec des non-Juifs, tels John Covel, professeur au Christ's College de Cambridge, avec lequel il correspondait en italien ${ }^{8}$ ou le pasteur Christian Theophilus Unger, auquel il écrivait en hébreu'. Sans compter que la réputation de l'érudit attirait de nombreux visiteurs, hommes de sciences et de lettres, et qu'on n'avait jamais vu autant de non-Juifs autour de la synagogue séfarade de Bevis Marks ${ }^{10}$ !

La synagogue représente, de fait, le centre de vie de toute société juive. Dès leur arrivée à Londres, les pionniers de la petite communauté s'étaient empressés d'ouvrir leur synagogue secrète dans Creechurch Lane ${ }^{11}$, entre Leadenhall Street et Duke's Place : la nouvelle congrégation avait pris le nom de Chaar Hachamayim (Porte des Cieux), et elle s'était progressivement organisée, se développant et prenant de l'ampleur. En 1662, John Greenhalgh estimait le nombre de fidèles à une centaine $\mathrm{d}^{\prime}$ hommes $^{12}$, mais en 1674 déjà, de gros travaux d'agrandissement du local de Creechurch Lane étaient engagés. Le nombre d'hommes seuls dépassa bientôt 200 , et il fallut songer à déménager. Les responsables entreprirent rapidement les démarches visant à la construction de la synagogue actuelle dans Bevis Marks. L'acquisition du bâtiment se fit au prix élevé de $2650 £$, réunies en grande partie sous forme de dons individuels concédés par les membres de la communauté. L'inauguration de la nouvelle maison de prières, en septembre 1701, coïncidait avec l'intronisation du nouveau haham, dont la première tâche fut de composer et de publier une prière en faveur du monarque Guillaume III $^{13}$; la cérémonie inaugurale eut lieu à quelques jours du nouvel an juif, sous la présidence des membres du Conseil - Isaac Israël Correa, Isaac Lopes Pereira, Abraham Vaes Martines, Isaac Israël Henriques, et Moses Francia ${ }^{14}-$, ceux-là mêmes qui avaient fait venir David Nieto. Les bancs de chêne sur lesquels les fidèles s'étaient assis dans Creechurch Lane furent incorporés au nouveau décor qui, dans la taille et la forme curviligne de ses fenêtres, sa galerie supérieure réservée aux femmes, son Arche Sainte, son pupitre, son candélabre et son arrangement général, ressemblait de façon impressionnante à la grande synagogue d'Amsterdam, ouverte en 1675. L'Arche Sainte témoigne de l'implication juive dans le commerce du bois avec l'Amérique du Sud au XVII ${ }^{\mathrm{e}}$ siècle : à la veille d'un périple au Brésil, le Conseil avait pu passer commande à ses affiliés marchands d'un chargement du meilleur bois de cèdre ${ }^{15}$. Les dix chandeliers symbolisent les Dix Commandements tandis que les douze colonnes soutenant la galerie renvoient traditionnellement aux douze tribus d'Israël. C'est à l'intérieur de ce bâtiment boisé et chaleureux qu'officiait David Nieto, prononçant plus de cinquante sermons par an, composant de belles prières sous sa plume de poète, célébrant les naissances, les mariages, et commémorant les décès. Plus de trois cents ans après, outre quelques discrets ajouts, l'installation de l'électricité en 1929, et celle du chauffage, l'ancienne synagogue est restée pratiquement inchangée ${ }^{16}$.

7 Les Séfarades de Londres étaient aux alentours de 520 en $1695^{17}$, de 1050 en 1720, et de 2000 en 1750 - n'évoluant plus beaucoup au cours du siècle suivant. Leur belle période d'essor se situe précisément au temps de David Nieto qui enregistrait jusqu'à vingt mariages par $a^{18}$ et qui pouvait constater la croissance du revenu annuel de la congrégation : $3400 £$ en 1702 et $6700 £$ en $1726^{19}$. Jusqu'en 1730, l'immigration draina un flux continu et régulier de réfugiés en provenance, directe ou non, du Portugal et d'Espagne, qui fuyaient l'Inquisition et jouissaient là d'une certaine forme de tolérance nouvelle et porteuse d'espérances autant que de confiance. Impressionné, Jacob Sasportes, rabbin de la congrégation séfarade entre 1664 et 1665, écrivait déjà alors à son ami Josiah Pardo: «We live at a time in which God has seen fit greatly to ameliorate the condition 
of his people, bringing them forth from the general condition of serfdom to freedom [...] We are free to practice our own true religion ${ }^{20}$ ».

Dès la réadmission en effet, l'autorisation de séjour accordée aux Juifs impliquait l'entière liberté de vivre où bon leur semblait, et nombre des barrières juridiques qu'ils pouvaient rencontrer ne faisaient que les inclure dans le cadre plus large de la communauté non anglicane. L'Acte de Tolérance de 1661 avait octroyé une reconnaissance légale à la diversité religieuse, en autorisant le culte public des dissidents protestants qui restaient dans le cadre de la Trinité. Considérant néanmoins que les liens entre l'Église établie et l'État étaient toujours indissolubles, l'Église et les dirigeants politiques continuèrent d'interdire aux non-Anglicans, jusqu'à la fin de la période hanovrienne, la pleine participation à la vie politique de l'Etat. Le Corporation Act de 1661 excluait des corporations municipales et commerciales ceux qui refusaient de recevoir le sacrement selon les rites de l'église d'Angleterre et les Test Acts de 1673 et 1678 disqualifiaient ces derniers des carrières politiques et de la fonction publique. Pour y avoir accès, il fallait nécessairement appartenir à l'Église établie.

Dissidents, Juifs et Catholiques étaient donc souvent victimes de la même législation parlementaire, alors que dans la plupart des autres pays européens, les Juifs étaient la cible de multiples restrictions spécifiques. En Angleterre aussi, certaines barrières juridiques - qui leur étaient plus particulièrement destinées - pouvaient entraver leur vie quotidienne, mais ne les visaient-elles pas plutôt en tant qu'étrangers? Ne se fondaientelles pas davantage sur un argument d'ordre commercial que religieux? Toujours est-il que les Juifs ne pouvaient devenir citoyens-résidents de la Cité, y posséder des magasins ni y faire du négoce de détail. L'Acte de Navigation (1660) réservait quant à lui aux Anglais de naissance le commerce colonial, et les statuts datant de la période précédant l'expulsion de 1290 (qui n'avaient pas été abolis) interdisaient aux Juifs de posséder des terres. Les Juifs ne pouvaient pas non plus devenir actionnaires de la Compagnie des Indes Orientales et les tarifs douaniers discriminatoires (alien duties) qui les frappaient, les rendaient moins compétitifs ${ }^{21}$. Dans les faits pourtant, l'absence de rigueur policière encourageait nombre de Juifs à contourner ces lois restrictives : les marchands séfarades non naturalisés pouvaient se dérober au Navigation Act en achetant des navires sous le nom de leurs commis anglais, et ceux qui souhaitaient appartenir à la noblesse terrienne se prenaient à enregistrer leurs acquisitions sous le nom de leurs employés chrétiens. À la Bourse de Londres, la fonction de marchands de titres (stockjobber) leur était ouverte sans aucune restriction et si, depuis $1697^{22}$, le nombre d'agents de change (stockbrokers) juifs était réduit à douze sur un total de 124 , ce chiffre leur était à l'époque proportionnellement très favorable - si l'on se rappelle que Londres comptait autour de 500000 personnes en 1700 , alors que la communauté juive avoisinait à peine le millier d'âmes!

10 Dans l'ensemble donc, les Juifs vivaient à Londres au début du XVIII ${ }^{\mathrm{e}}$ siècle, une belle période de leur histoire. Très vite, ils oublièrent d'être inquiétés, de se cacher, de se faire discrets. Les abords de la synagogue devinrent animés à la sortie des offices - et notamment le dimanche; Bevis Marks et Bury Street s'emplirent de fidèles insouciants aux discussions parfois bruyantes. Le Conseil prit trois nouvelles mesures au cours de la seule année 1701: les membres de la congrégation se voyaient interdire les attroupements dans le quartier; au regard de l'injonction royale de s'abstenir des jeux le dimanche, ils ne devaient plus se rencontrer ce jour dans des lieux publics, ou même privés, pour y jouer ; les cortèges accompagnant la mariée lors des célébrations devraient 
désormais se réduire aux seuls parents et frères. Toute transgression donnait lieu à une amende $^{23}$.

11 Le transport - à cheval ou en voiture - n'étant pas autorisé le samedi dans la religion juive, les fidèles ont pris l'habitude, à travers les générations, de s'installer à distance raisonnable de leur synagogue. À Londres, la grande majorité des Juifs vivait dans la commune de St James (Dukes Place), qui devint dès 1722 le quartier juif de la capitale : plusieurs synagogues s'y trouvaient - dont celle, séfarade, de Bevis Marks - et on y rencontrait des membres des deux communautés, quelques bouchers, un laitier, voire nombre de petites échoppes promettant de répondre aux mille besoins quotidiens ; « $\mathrm{Au}$ Soleil Levant » était l'enseigne d'Abraham Benedictus, fabricant de chandelles dans la rue Houndsditch, tandis que "Sam's Coffee House" était l'adresse indiquée pour la restauration des hommes d'affaires juif ${ }^{24}$. De nombreux marchands juifs étaient domiciliés dans St Mary Axe, Fenchurch Street, Leadenhall Street, Bishopsgate Street, Crutched Friars, et Great St Helen's ${ }^{25}$. Mais les Juifs habitaient également dans les communes de St Katherine Creechurch, All Hallows, London Wall et St Andrew Undershaft ${ }^{26}$. À l'instar des Anglais de la haute société, certains riches Séfarades disposaient, en plus de leur domicile à Londres intra-muros, d'une résidence secondaire, acquise ou louée dans les villages à proximité ou la campagne environnante, pour y passer les weekends ou les étés. Dès 1675, Alvaro da Costa avait fait l'acquisition d'une maison à Highgate, où le rejoignirent bientôt les familles de ses cousins Fernando Mendes et John Mendes da Costa. En 1715, c'est Antony Mendes qui s'offrait à Highgate une maison avec patio, suivi en 1721 par John Mendes da Costa qui devenait propriétaire de Baron House, belle bâtisse dont le souvenir a été conservé sur une peinture du XIX siècle ${ }^{27}$. Les propriétés des da Costa étaient encore nombreuses dans la région, mais la plus impressionnante semble avoir été Copped Hill à Totteridge (à quelques kilomètres au nord de Highgate), achetée en 1721 par Joseph, l'un des fils d'Alvaro da Costa. Le tracé de ses superbes jardins bordés d'arbres sur une étendue vertigineuse et quasi royale, apparaît sur une gravure datant de $1739^{28}$.

Dès les premières heures de la réadmission, les Crypto-Juifs ${ }^{29}$ se réfugiant à Londres au cours des années 1650 avaient été des marchands ${ }^{30}$, dont le commerce se concentrait dans les domaines qui, du fait de leur langue, leurs relations ou leur expérience personnelle, les avantageaient. Antonio Fernandes Carvajal avait été importateur de vins et c'est la famille Francia qui reprit son affaire. En général néanmoins, même après que le Traité de Methuen $^{31}$ de 1703 eut donné l'avantage aux vins portugais, désormais moins taxés que les vins français, le commerce des vins était dominé par les marchands des fabriques anglaises implantées à Lisbonne et à Porto ${ }^{32}$. Les marchands juifs londoniens commerçant avec le Portugal, penchèrent alors plutôt pour la spécialisation dans l'export du vêtement anglais et l'import des produits coloniaux et de l'or. La communauté séfarade de Londres comptait ainsi de grands négociants tels les frères Francia, Gomez Rodriguez, Alvaro da Costa ou Peters et Piers Henriques. Les pierres précieuses et les diamants occupaient également une place privilégiée au cœur des échanges, et ce, jusqu'à la fin du siècle des Lumières : les Juifs exportaient en Inde le corail et importaient en retour des diamants qu'ils faisaient tailler et polir à Amsterdam pour les revendre ensuite à Londres; dès le début du XVIII ${ }^{e}$ siècle, ce sont les familles Franco, Mendes da Costa, et Salvador qui pesaient le plus dans le négoce du diamant. Entre 1717 et 1766 (à l'exception de quatre occurrences), l'importation annuelle de diamants par les Juifs était largement supérieure à celle des non-Juifs. Outre les diamants, le négoce avec l'Inde concernait l'importation de 
vêtements, mais celle-ci était exclusivement réservée à la Compagnie des Indes Orientales. Les Juifs en étaient officiellement exclus, mais ils participaient très largement aux grandes ventes publiques des produits de ces importations à Londres, se spécialisant dans l'achat du vêtement d'occasion. Ils y occupaient du reste une place assez importante pour que ces ventes soient reportées lorsqu'on les avait programmées pendant les fêtes juives $^{33}$. Les échanges commerciaux étaient importants, voire florissants, entre les marchands séfarades de Londres et leurs coreligionnaires à l'étranger, à Amsterdam, Hambourg, Bordeaux, Bayonne, Livourne, mais aussi dans les colonies anglaises de la Jamaïque, la Barbade ${ }^{34}$, et le Surinam ${ }^{35}$. Les Juifs étaient en revanche absents de certaines activités lucratives, telle celle du sucre, par exemple, qui impliquait à l'époque le commerce d'esclaves, auquel la communauté juive dans l'ensemble, ne semble jamais avoir pris part ${ }^{36}$.

Lorsque David Nieto prit ses fonctions à la tête de la congrégation, les Séfarades de Londres comptaient parmi eux un grand financier du nom de Solomon de Medina (1650-1730), arrivé à Londres en 1672. Durant les années 1690, l'entreprise « Machado \& Pereira ", dont il était l'agent, fut fournisseur en pain de l'armée du roi Guillaume III en Irlande et, à plusieurs reprises, il avança les fonds, pour n'être remboursé que bien plus tard par le gouvernement. En signe de reconnaissance pour ses services rendus au pays, le monarque qui l'estimait assez pour avoir dîné chez lui, le fit chevalier en 1700, privilège dont il fut le premier Juif à jouir en Angleterre ${ }^{37}$. Il fut élu au sein du Conseil en 1676, puis en $1702^{38}$. Il fut encore vivandier des armées royales au cours des années 1707, 1708, 1709, 1710 et $1711^{39}$, mais il semble qu'il vivait à cette époque en Hollande, laissant Moses de Medina gérer ses affaires à Londres.

Abraham Mocatta, fidèle privilégié de la congrégation de Bevis Marks était, quant à lui, courtier en or à la Banque d'Angleterre. Les marchands séfarades importaient l'argent de Cadix et l'or de Lisbonne et Mocatta, qui entretenait des liens étroits avec eux, savait pertinemment qui disposait de stocks de lingots à vendre et qui cherchait à en acheter. Il fut particulièrement prospère. En 1721, il commanda l'écriture d'un rouleau de Thora au profit de la synagogue, la réalisation de ses ornements et la confection de son manteau, et l'orfèvrerie comme les broderies étaient réputées pour leur qualité et leur finesse. Le coût extrêmement onéreux d'une telle acquisition, ajouté au verset qu'il fit graver sur les grenades d'argent ornant le rouleau, suggèrent une année commercialement florissante : « Isaac sema cette année-là et récolta cent fois plus ; le Seigneur le bénit ${ }^{40}$ ".

La communauté séfarade comptait donc bien quelques Juifs nantis, le plus souvent marchands ou impliqués dans le monde de la finance, sur lesquels elle fondait sa prospérité et sa belle croissance à l'aube du XVIII ${ }^{\mathrm{e}}$ siècle : ce n'étaient plus $50 £$ à l'année, traitement de Jacob Abendana entre 1681 et 1685, qu'offrait le Mahamad à David Nieto en 1701, mais bien $100 £$ (qui devinrent bientôt $150 £$ ), en sus du charbon gratuit, d'une prime de $10 £$ annuelle à l'occasion de Pourim (la fête d'Esther), d'un logement de fonction et de 82,15 $£$ pour le meubler ${ }^{41}$ ! Nombreux étaient aussi ceux qui vivaient plus modestement du savoir qu'ils avaient importé de leurs contrées d'origine : graveurs, clercs, confiseurs et pâtissiers, brodeurs, tailleurs, traducteurs, enseignants, professeurs de langues, maçons, laboureurs, tailleurs de diamants, bijoutiers, fabricants de crayons et vitriers. Entre 1706 et 1711, Senhora Leonor Morais fut employée par la congrégation à la confection de pâtisseries et confiseries pour la présentation du don annuel au maire ${ }^{42}$. Abraham Lopes de Oliveira (1657-1730), orfèvre, était quant à lui rémunéré pour prendre soin de l'argenterie de la synagogue Bevis Marks. La mobilité sociale touchait peu les 
nouveaux immigrants juifs en Angleterre et nous n'avons pas connaissance de Juifs immigrants pauvres qui aient prospéré dans les affaires ${ }^{43}$. La difficulté et la pauvreté étaient enfin le lot quotidien de maintes personnes âgées ou malades, des veuves et des orphelins, mais aussi des réfugiés en provenance d'Espagne et du Portugal, fuyant l'Inquisition et vivant souvent de petits emplois peu rentables, voire de la mendicité.

\section{Une société solidaire, férue de lettres et d'éducation}

L'assistance aux pauvres, la tsédaka, est l'une des composantes essentielles du judaïsme. Rappelée à maintes reprises dans la Thora, elle s'impose pratiquement à tous : chacun ${ }^{44}$ des membres de la communauté juive est tenu de remettre aux plus démunis un dixième (la dîme) au moins de ses gains. Étymologiquement dérivé de la racine tsédek (justice), le concept de tsédaka ne se conçoit plus simplement comme le résultat facultatif d'une bonne volonté ou d'un noble sentiment, mais comme un devoir de justice. Les Sages d'Israël considèrent la charité comme une restitution au pauvre de ce qui lui revient: Dieu fait de l'homme Son intermédiaire pour lui permettre de connaitre à son tour, en le répétant, le geste divin du don ${ }^{45}$. La création de toute communauté juive passe donc nécessairement par la fondation d'institutions caritatives - d'autant plus indispensables dans la société anglaise des Poor Laws qui ne connaissait pas encore la sécurité sociale, et où la workhouse n'était pas toujours compatible avec le mode de vie juive.

Dès les premiers jours de la réadmission, la congrégation séfarade de Londres avait eu à sa charge de nombreuses familles démunies, souvent en provenance des pays où sévissait encore l'Inquisition. Dans la pétition de 1689, adressée au Parlement par la communauté juive $^{46}$ et intitulée The Case of the Jews Stated, les auteurs faisaient déjà état d'une population juive dont la moitié était composée de personnes vivant difficilement de leur labeur ou à la charge des plus nantis ${ }^{47}$. La correspondance du Mahamad fait aussi largement référence à la pauvreté : un courrier datant de l'hiver 1703 rappelait que de nombreuses familles juives londoniennes accueillaient et hébergeaient les réfugiés démunis, et une lettre du Conseil adressée en 1705 à la communauté de Livourne faisait état des lourdes charges financières imposées à la congrégation par l'afflux de réfugiés, notamment en provenance du Portugal. En 1710, les aides aux pauvres allouées par la congrégation à des immigrants en provenance d'Italie et de Barbarie étaient élevées et l'immigration séfarade en provenance de la péninsule ibérique ne s'affaiblit que bien plus $\operatorname{tard}^{48}$. Dans le second volume des archives de la synagogue Bevis Marks, consacré aux mariages célébrés jusqu'en 1837, plusieurs entrées de couples sont accompagnées de la mention Vindos de Portuga ${ }^{49}$. Ces couples arrivaient à Londres et célébraient à nouveau leur mariage selon les rites de la tradition juive -qu'ils avaient momentanément abandonnée en raison de l'Inquisition. Seize remariages furent enregistrés au point le plus haut de la courbe en l'an 1726, puis de nouveau en 1728, l'année du décès de David Nieto. En 1726, 1727 et 1728, les comptes rendus du Mahamad font même mention de sommes versées aux capitaines des navires ( $254 £$ et $4 \mathrm{~s}$. en 1728 ) pour payer le transport de ces réfugiés sans le sou ${ }^{50}$. On aidait alors les personnes âgées, les malades, les veuves et les orphelins à survivre. On donnait un coup de pouce aux jeunes en quête de travail en leur prêtant un peu d'argent - de quoi débuter en tant que colporteurs ou revendeurs de vêtements de seconde main; le commerce de rue de fruits importés, telles les oranges ou la rhubarbe, était notamment assez typique. 
18 La prise en charge des malades et l'accomplissement des derniers devoirs envers les défunts occupent encore une place primordiale dans le judaïsme et dès la réadmission, des bénévoles privés s'étaient chargés de ces responsabilités. En 1709, peu après l'inauguration de l'association régulière Hebra de Bikur Holim (Association pour les visites aux malades), David Nieto prononçait un sermon, intitulé « Los Triunfos de la Pobreza » (Les triomphes de la pauvreté), publié et dédicacé aux responsables de l'institution - le trésorier Abraham Nunez et les administrateurs Ab Fernandez Salazar et David de Meza ${ }^{51}$. Le dispositif s'élargit au fil des années avec notamment le fonds, inauguré en 1724, qui devait assurer une dot de $60 £$ aux jeunes filles séfarades orphelines ${ }^{52}$.

L'action caritative de la congrégation ne s'arrêtait pas aux seules frontières de l'Angleterre. Deux fonds étaient déjà prévus dans le cadre des statuts d'origine, gérés par deux trésoriers distincts et alimentés régulièrement par les dons des fidèles: Cautivos était réservé à la rançon des captifs juifs, victimes des pirates barbaresques; soixante ducats étaient ainsi prélevés en 1705 pour racheter Aron Affia, Abraham Perez et Joseph Haïm Esquenazy, captifs des Chevaliers de Malte. Les prisonniers étant généralement vendus comme esclaves, le Conseil puisa à plusieurs reprises dans le fonds Cautivos pour racheter les prisonniers juifs des mains de ces «Tyrans de Malte ${ }^{53}$. Le fonds Terra Santa était originellement destiné à soutenir les divers établissements religieux de Terre Sainte et notamment de Jérusalem, Hébron et $\mathrm{Safed}^{54}$, représentés par les prestigieux visiteurs qui se succédèrent à Bevis Marks : les rabbins Simon bar Yaakov Vahbendanon en 1705, Abraham Rovigo de Jérusalem, Abraham Gedalla en 1726, et Moché Israel en 1728. La correspondance du Mahamad fait encore état de nombreuses lettres de demandes d'aide en provenance d'autres communautés juives; si la priorité allait traditionnellement vers les autres Séfarades à travers le monde, la copie d'une lettre écrite en 1710 par le trésorier Moses de Medina est conservée dans les archives de la congrégation: Moses y demande à ses proches parents, Joseph de Medina et ses fils d'Amsterdam, de partager entre «nos pauvres frères de Pologne, touchés par les calamités », la somme de 2275,11 florins $s^{55}$. Enfin, lorsque l'aide pécuniaire ne s'avérait d'aucun secours, la communauté se repliait sur la prière: au temps où les autodafés représentaient au Portugal des attractions très courues et où de nombreux Juifs croupissaient dans les prisons de l'Inquisition, une prière était prononcée annuellement à Bevis Marks le jour de Kippour pour « nos frères emprisonnés dans les cachots de l'Inquisition » ${ }^{56}$.

De tous temps, l'éducation a représenté une priorité au sein des communautés juives. Dans le monde séfarade, les statuts de Valladolid de $1432^{57}$ demandaient aux congrégations de réserver un fonds devant permettre la gratuité de l'instruction pour les enfants. Dès 1664 à Londres, l'école primaire ouvrait ses "Portes de l'espoir ", Chaaré Tikva, pour éduquer la jeunesse juive. L'illettrisme était tenu en horreur et cela était palpable dans l'exigence de perfection manifestée à la synagogue : l'officiant n'avait pas droit à l'erreur et sa lecture ne souffrait aucune faute, sous peine d'une amende de $25 \mathrm{p}$ par irrégularité 58 ! La première institution éducative en faveur des orphelins -Chaaré ora veavi yetomim (Portes de lumière et père des orphelins) naissait en 1703, et David Nieto délivra le sermon d'inauguration, développant le verset : « dans sa sainte résidence, Dieu est le père des orphelins " $^{59}$, ainsi que l'adage talmudique stipulant que: "celui qui éduque un orphelin est considéré par le Texte comme son géniteur ». L'un des orphelins, Isaac Henriques Lopes, ainsi que les jeunes Moses et Isaac Nieto, prirent à leur tour la parole le samedi suivant, traitant de la charité «comparable en importance à tous les autres préceptes ${ }^{60}$. L'institution était chargée d'habiller douze garçons orphelins, de 
subvenir à leurs besoins, de les éduquer et de les former à l'apprentissage d'un métier. Chaque hiver, les élèves recevaient un grand manteau et cinq shillings d'argent de poche ${ }^{61}$ :

These children are not only instructed in the Jewish literature, but likewise to read, write and account in English; and after having been at least three years at school, have each of them twenty pounds given him for advancing them in the world ${ }^{62}$.

Dans l'œuvre sur le judaïsme qu'il publiait à Londres en 1706, Isaac Abendana (1650-1710), professeur d'hébreu à Cambridge puis Oxford, décrivait les pratiques et la juridiction juives, les dîmes, l'importance de la prière, et consacrait un long chapitre au caractère fondamental de l'école au sein de la communauté juive :

The necessity as well as usefulness of schools for the instruction and education of youth, is so apparently manifest that, in the opinion of our doctors, mankind could scarcely subsist without them; because, otherwise men could neither preserve the dignity of their nature, as reasonable creatures, nor have anything but their outward shape, to distinguish them from brutes ${ }^{63}$.

Isaac Abendana avait également achevé en 1671 une traduction latine de la Mishna ${ }^{64}$, et publié des calendriers juifs en 1695,1696 , et les années suivantes. Il était le frère de Jacob Abendana, guide spirituel de la communauté séfarade londonienne entre 1681 et 1685, et entretenait comme lui une correspondance soutenue avec plusieurs savants chrétiens dont Ralph Cudworth, professeur à Christ's College. Le haham Nieto reçut d'ailleurs un courrier de John Covel, collègue de Cudworth, daté du 18 janvier 1706 et commentant précisément l'un des almanachs d'Abendana ${ }^{65}$. David Nieto était de fait réputé pour ses connaissances en astronomie et sa science des calendriers; en 1693, il avait composé Pascalogia, œuvre dans laquelle il discutait des différences de datation de Pâques entres les églises grecque et latine et le judaïsme. Ce travail avait été généré par la célébration de Pâques le 22 mars 1693, et celle de Pessah le 21 avril 1693, alors qu'en règle générale la Pâque juive précède toujours les Pâques chrétiennes. Le haham avait dédicacé Pascalogia à Francesco Maria de Medici, le 2 mars 1700 à Livourne, ce qui met en lumière les relations amicales que pouvaient entretenir rabbin et cardinal à l'aube du XVIII ${ }^{e}$ siècle ${ }^{66}$. A la tête de la congrégation séfarade de Londres, David Nieto s'attela à préparer un almanach adapté aux latitudes britanniques, comprenant les dates de nouvelle lune, des jeûnes, des fêtes (pour 83 années), des éclipses pour le méridien de Londres (pour 23 années), les horaires du shabbat à Amsterdam et Londres, ainsi que ceux des prières à Bevis Marks (Solomons 34) : Bina laïtim (Connaissance des temps) paraissait en 1717 et, dès 1723, sur résolution du Conseil, ce calendrier était officiellement adopté en Angleterre ${ }^{67}$. Tous les vendredis après-midi, le bedeau de la synagogue séfarade se dirigeait avec une petite escorte vers Duke's Place pour saluer la congrégation ashkénaze au nom du Conseil et l'informer de l'heure de l'entrée du shabbat. La coutume survécut de nombreuses années après la publication de calendriers imprimés et annuels, pour ne s'éteindre qu'au $\mathrm{XX}^{\mathrm{e}}$ siècle ${ }^{68}$.

Outre ses dons en astronomie, David Nieto était poète et plusieurs de ses compositions, signées de son nom de plume $\mathrm{DaN}^{69}$, apparaissent dans un recueil de poèmes écrits par des Juifs italiens, intitulé Kol éguev (Son d'amour) et publié à Livourne en 1846 par le haham Abraham Benedetto Piperno (Solomons 5-7). En 1720, il participa activement à la publication, à Londres, de la première traduction espagnole versifiée des Psaumes : Espejo fiel de vidas (Miroir fidèle de la vie). Ce travail d'art, si précieux pour la communauté séfarade hispanophone londonienne, était l'œuvre de Daniel Israël Lopes Laguna (1650-1723) - qui y consacra plus de vingt années de labeur. Avec ses cinquante pages 
introductives, les dédicaces rimées composées en espagnol, portugais, latin et anglais par des membres de la communauté, les lettres d'approbation - dont celle du haham David Nieto - et les enluminures, l'œuvre est superbe! Une phrase d'introduction présente chacun des psaumes, renvoyant parfois aux propres souffrances de l'auteur livré aux mains des cruels bourreaux de l'Inquisition, mais qui, humble et pétri de reconnaissance, rend hommage à l'Eternel dans un poème final où il exprime sa gratitude et qu'il conclut en rappelant: "Solo en Dios la confianza!" (Lopes Laguna 339). L'ouvrage est encore particulier en ce qu'il révèle les talents de trois femmes séfarades aristocrates de Londres qui apportèrent ainsi leur contribution à la poésie juive espagnole : Sara Foncesca Pina y Pimentel, Manuela Nunes de Almeida et Bienbenida Cohen Belmonte : elles étaient des parentes du mécène Mordekhay Nunes de Almeida qui permit la publication de cette traduction, et chacune dédicaça une composition poétique à l'auteur pour saluer son œuvre; ces trois derniers hommages laissent là le témoignage de voix féminines aptes à manier poétiquement la langue de la lointaine Espagne.

L'un des tributs à Daniel Lopes Laguna était paraphé par l'un des médecins de la congrégation de Bevis Marks, Sequeiro Samundo. La médecine est traditionnellement une spécialité très respectée dans le monde juif et peut-être tout particulièrement dans le monde séfarade - notamment en Espagne et au Portugal. Nombre des médecins, chirurgiens et pharmaciens portugais étaient des Crypto-Juifs. Parmi eux, plusieurs réfugiés immigrèrent en Angleterre et furent autorisés par le Royal College of Physicians à pratiquer la médecine, tels les médecins Hector Nunes et Rodrigo Lopes au XVI ${ }^{\mathrm{e}}$ siècle ou

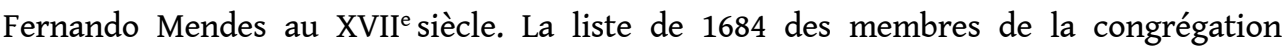
séfarade mentionne trois médecins ${ }^{70}$ et leur nombre s'accrut encore au XVIII ${ }^{\mathrm{e}}$ siècle. David Nieto lui-même était médecin, diplômé de l'université de Padoue, et certaines sources témoignent qu'il continua à prodiguer des soins à Londres ${ }^{71}$. En Angleterre, Juifs et dissidents n'avaient pas accès aux universités nationales et ils se formaient donc en Italie ou aux Pays-Bas. Jacob de Castro Sarmento put néanmoins compléter le titre obtenu à l'université de Coimbra par le diplôme de médecin qu'il prépara par correspondance dans l'une des universités écossaises, le Marischal College d'Aberdeen. Il fut le médecin de l'ambassadeur portugais à Londres, Sebastiao Carvalho e Melo qui devint par la suite le marquis de Pombal. Dans une correspondance très soutenue ${ }^{72}$ avec le Portugal, il mettait en garde les hommes d'état contre les épidémies et il laissa de nombreuses publications portant sur la variole ${ }^{73}$. Maitrisant tant le latin et le portugais que l'anglais, il fut élu à la Royal Society et s'illustra en tant que fondateur du Beth Holim, l'hôpital juif qui vit le jour en 1748. Jacob de Castro Sarmento était un ami intime du rabbin David Nieto, et il le remplaça plusieurs fois lorsque, vers la fin de sa vie, affaibli et malade, il ne pouvait délivrer son sermon aux fidèles de Bevis Marks. Le médecin prononça d'ailleurs une oraison funèbre très touchante, en 1728 , à l'occasion du décès du haham dont il avait été si proche $^{74}$. Solidaires, charitables et éduqués ou du moins, grands amateurs de sciences et de lettres, les Séfarades de Londres vivaient tranquillement à l'ombre protectrice de la tolérance anglaise; le guide spirituel qui s'installait là découvrait toutefois très rapidement l'ampleur du défi qu'il devrait relever au sein de cette petite communauté à la "préhistoire » très particulière. Car, ainsi que l'écrivait si justement Albert Hyamson: " the Sephardim of England have not only a history: they also have a prehistory »" 


\section{Une congrégation en quête de son identité spirituelle}

Les derniers rayons du soleil couchant de la liberté en Espagne à la fin du $\mathrm{XV}^{\mathrm{e}}$ siècle virent 200000 Juifs quitter ce pays dans lequel ils avaient vécu plus de mille ans. En 1492 en effet, Ferdinand II d'Aragon et Isabelle de Castille expulsaient les Juifs de leur territoire. L'invasion des Almohades au XII ${ }^{\text {e }}$ siècle, puis la reconquête chrétienne et l'institution de l'Inquisition, avaient déjà mis un terme à cette ère que l'on a nommée l'âge d'or du judaïsme espagnol. En 1492 toutefois, l'édit d'expulsion marquait véritablement la fin d'un long chapitre d'histoire juive. Les exilés abandonnaient leur patrie et leurs biens ; ils étaient jetés sur des chemins hostiles, dans la souffrance et l'incertitude de leur destin. Nombreux furent alors les Juifs qui s'installèrent dans le royaume voisin du Portugal, mais en 1497, le roi Manuel Ier cédait aux pressions diplomatiques des rois catholiques, et ordonnait lui aussi l'expulsion des Juifs du pays -mesure qu'il faisait suivre un an plus tard par l'interdiction d'émigrer et le baptême forcé. Les Juifs s'orientèrent vers l'est et s'installèrent, tant bien que mal, sur les bords de la Méditerranée, à Venise en Italie, en Turquie, et dans d'autres pays d'Asie. La lumière s'était éteinte pour les Juifs en Espagne. De temps à autre, l'obscurité s'éclairait par les flammes rougeoyantes des autodafés. Les Crypto-Juifs qui, un temps trop faibles pour résister à la tentation, avaient extérieurement abandonné la foi de leurs pères, se portaient à présent, tels des sacrifices d'expiation, sur l'autel de l'Inquisition. Certains parvinrent néanmoins encore à s'échapper, à fuir les filets et la traque de l'Inquisition. Conduits par les remords de leur conscience, ils cherchèrent un foyer dans le nord de l'Europe, afin de revenir à leur ancienne foi et de professer, librement devant les nations, leur croyance dans le Dieu d'Israël ${ }^{76}$.

Le vécu des Crypto-Juifs impliquait une identité juive fragmentaire et instable. Ils étaient nombreux à se caractériser par une pratique religieuse défaillante et une foi confuse et faible, du fait que leurs ancêtres immédiats avaient vécu la majeure partie de leur vie en tant que Catholiques et non en tant que Juifs. Au cours de la seconde moitié du XVII ${ }^{e}$ siècle, lorsque les Nouveaux Chrétiens commencèrent à affluer vers l'Angleterre, ces personnes d'origine juive en provenance de la péninsule ibérique avaient été coupées d'un judaïsme intégral et pleinement vécu depuis plus d'un siècle et demi. Le judaïsme qu'on leur avait transmis était tronqué, clandestin, et dépourvu du support institutionnel que représentent les synagogues et maisons d'étude. Ils avaient approfondi leur connaissance du judaïsme grâce au passage - en Espagne et au Portugal - de Juifs pratiquants en voyages d'affaires, mais aussi à travers la lecture d'une littérature polémique anti-juive ou les sermons prêchés lors d'autodafés... Si les Crypto-Juifs n'avaient jamais abandonné leur judaïsme, leur observance religieuse s'était bien souvent atrophiée au fil des générations, la surveillance resserrée de l'Inquisition rendant difficile et périlleuse la transmission de la connaissance de l'hébreu, des pratiques liturgiques et de l'observance des rites juifs. Sans compter que les persécutions de l'Inquisition touchaient les Nouveaux-Chrétiens ${ }^{77}$ sans distinction, y compris ceux qui avaient déjà cessé de pratiquer le judaïsme en secret ; lorsque ces derniers échappèrent aux griffes de l'Inquisition pour vivre en Angleterre, ils ne réintégrèrent pas toujours l'ensemble de la pratique du judaïsme. Ils pouvaient se déclarer Juifs mais négliger par exemple de se circoncire - comme ce fut le cas de Fernando Mendes et Alvaro da Costa ${ }^{78}$. 
Une fois installée dans un pays tolérant, la grande majorité des Crypto-Juifs entamait un processus de ré-judaïsation, réapprenant les rites, les croyances et les émotions juives. Lorsque ces Nouveaux-Chrétiens s'installaient dans des communautés juives majeures comme Amsterdam ou Venise - dotées de structures établies et de ressources intellectuelles à même de les rééduquer et de les réintégrer dans la vie juive, ils devenaient généralement des Juifs pratiquants, capables de transmettre à leur tour leur religion à leurs enfants et à leurs petits-enfants. Si ces Crypto-Juifs s'installaient en revanche dans une communauté juive mineure, ils étaient plus largement susceptibles de s'immerger complètement dans la société d'accueil et de s'assimiler ${ }^{79}$. Malgré ses liens avec la communauté d'Amsterdam, la petite colonie juive de Londres se situait aux confins de la vie juive structurée en Europe. Petite et négligeable, elle n'était réputée ni pour sa piété, ni pour ses grands érudits en Thora - qui faisaient défaut. Lorsque le haham David Nieto s'installa à Londres en 1701, la tâche se présenta dans toute son ampleur - la foi constituant le dossier brûlant à l'ordre du jour : il lui fallait éclairer la voie, renforcer la pratique religieuse, pointer du doigt les concepts biaisés et les croyances étrangères, et affermir la foi en ravivant l'étincelle qui avait guidé jusque-là toutes ces femmes, tous ces hommes au cours de leurs obscures pérégrinations.

David Nieto s'attacha très rapidement à faciliter l'intégration des réfugiés au sein de la synagogue : il publia une traduction de certaines prières des Jours redoutables, intitulée Bakachot (Suppliques), à l'intention du fidèle d'origine crypto-juive, étranger à la langue hébraïque. Le fascicule, distribué gracieusement, comprenait notamment quelques suppliques traduites en espagnol et une fervente exhortation à la pratique religieuse; il servait d'étape intermédiaire aux nouveaux arrivants et le haham devait l'enrichir au fil des années ${ }^{80}$. Il importe de souligner ici le poids des idées à Bevis Marks. Ce qui peut frapper l'observateur moderne est cette fougue que les fidèles pouvaient investir dans la lutte pour les concepts, et la méfiance qu'ils témoignaient à l'égard de toute opinion en apparence novatrice. Accrochés aux bases rudimentaires survivantes de leur patrimoine idéologique d'origine, ils se dressaient jalousement face à qui menaçait d'y opérer la moindre brèche, fût-il leur haham lui-même ! Deux années seulement après son arrivée, le 20 novembre 1703, David Nieto prononça un sermon sur la Providence divine, qui fit l'effet d'un coup de tonnerre et souleva la controverse au sein de la congrégation : il avait avancé que la pensée juive ne reconnait aucun pouvoir à la Nature, simple rideau voilant Dieu. Dieu est la Nature. Le Roi David n'avait-il pas clamé, bien avant que ne naisse le concept même de la Nature dans la pensée occidentale : «C'est [Dieu] qui couvre le ciel de nuages, prépare la pluie pour la terre, fait pousser l'herbe sur les montagnes ${ }^{81}$ ? Les propos étaient limpides, mais le haham érudit fut accusé d'adhérer dans son exposé aux doctrines panthéistes hérétiques du philosophe juif Baruch de Spinoza (1632-1677) ${ }^{82}$. Au cœur de la guerre de succession espagnole, alors que d'aucuns se battaient pour survivre, les Séfarades de Londres se passionnèrent pour cette polémique bouillonnante qui naquit sur les concepts de Dieu et de Nature, et qu'on aurait pu croire le fait d'ecclésiastiques séparés des réalités quotidiennes par les murs de leur maison d'étude. Sur le conseil d'Aaron Hart, responsable de la communauté ashkénaze de Duke's Place, le cas fut finalement soumis à un observateur extérieur célèbre, le rabbin Tzevi Ashkénazi de Hambourg. "We do not ignore how pernicious and sinful it is to originate dissensions in a congregation" précisaient les opposants, assoiffés d'entendre "the Truth of our Holy Law on the point in question, so that we may [...] know what should be believed, and so obviate different opinions in such an important matter ${ }^{83}$. David Nieto développa sa position sur la question 
dans un essai de 94 pages intitulé De La Divina Providencia et, en août 1705, le rabbin Tzevi l'appuya et la fit publiquement valoir, notant vers la fin de son courrier :

We must thank H.H.R. David Nieto, whom God preserve, for the sermon he preached to warn the people not to allow themselves to be led away by the opinion of philosophers who treat on Nature [...] and he enlightens the eyes with the true belief, which is that everything comes from the providence of God. I say, may God fortify his strength and valour, and all, who, after having seen these words, shall think hardly of him, in my opinion, incur $\sin ^{84}$ (Solomons 17).

Avec justice et fermeté, la crise au sein de la congrégation fut jugulée : on avait rappelé à cette occasion que Dieu est le maître d'œuvre de tout ce que les philosophes attribuent à la Nature ${ }^{85}$.On avait également suscité la légitimation du haham à l'échelle européenne et dans le monde ashkénaze, puisque le rabbin Tzevi ainsi que les juges rabbiniques Solomon Hildesheimer et Aryeh Löb Lodzker qui signèrent la reconnaissance de son travail, étaient tous trois des Ashkénazes. Les fidèles étaient certes éclairés, mais d'autres champs d'action se profilaient à l'horizon. En raison de son vécu historique particulier, la communauté éprouvait des difficultés à embrasser toute la législation rabbinique, cette tradition « orale » qui s'était perpétuée au fil des siècles aux côtés de la Loi écrite, la Bible. Certains Séfarades d'origine crypto-juive s'avéraient particulièrement perméables à différents courants hérétiques comme celui des Néo-Karaïtes ${ }^{86}$,le sabbataïsme ${ }^{87}$ ou le déisme. Ainsi que le rappelait David Nieto :

Il était un temps où Dieu régnait sur Israël en maître incontesté, sur le Mont Sion et Jérusalem, [...] un temps où les sages d'Israël étaient divinement inspirés [...], un temps où toute la maison d'Israël orientait son regard et ses attentes vers ses juges et ses anciens, faisant d'eux son seul soutien et son unique guide pour appréhender la Loi écrite [...], un temps où les maisons d'étude ne connaissaient pas la controverse et la dispute, mais seulement la justice et la paix, un temps où les sages d'Israël étaient unanimes et clairs dans leur discrimination du pur et de l'impur ${ }^{88}$.

L'exil et les persécutions avaient toutefois assombri ce tableau de clarté et, dans nombre de sermons, de tracts et d'écrits philosophiques à l'intention de ses fidèles, le haham tentait de mettre les idées au clair, encore et toujours, et de défendre le judaïsme rabbinique contre ses détracteurs. En 1714, il publiait à Londres son étude philosophique majeure Maté DaN (la Verge de DaN) : en cinq chapitres écrits sous forme de dialogues, et en guise d'écho au Kouzari du rabbin, philosophe et poète Juda Halévy (1086-1145) ${ }^{89}$, il y prenait la défense de la Loi Orale. À ceux qui lui refusaient toute autorité, David Nieto répondait qu'elle avait été la toute première en vigueur : Sous quelle forme Dieu s'était-Il donc adressé à Adam pour lui enjoindre de ne pas consommer du fruit défendu? Comment avait-Il ordonné à Abraham de se circoncire ? D'où les hommes savaient-ils que le vol ou l'adultère était prohibé ? La Loi n'avait pas encore été consignée par écrit ! La transmission avait été orale et s'était poursuivie au travers des familles, au fil des générations. D’où avons-nous appris quel était le membre concerné par la circoncision? D'où savons-nous si le mois biblique est lunaire ou solaire, quels sont les textes à insérer dans les phylactères ou les règles de l'abattage rituel ? La Thora ne le précise pas... N'est-il pas nécessaire d'admettre que tant de données sont passées dans le vécu du peuple par le biais de la transmission orale ? N'est-il pas nécessaire d'admettre aussi que la Thora écrite ne peut pas être appréhendée sans l'aide précieuse et indispensable de la Thora orale ${ }^{90}$ (Nieto 6-8) ? En cinq débats imaginés entre le sage juif et le roi des Khazars, David Nieto cumulait les arguments et réduisait au silence les détracteurs de la Loi Orale, plus largement connus sous le nom de Karaïtes. Il se voulait didactique, formateur, à la portée de tous : «J'implore ceux qui enseignent la Thora de transmettre à leurs élèves les trois 
premiers dialogues de ce livre et de bien les expliquer : c'est la raison pour laquelle je les ai rédigés dans une langue claire et simple ${ }^{91}$ ». Dans son œuvre intitulée Ech Dat (le Feu de la loi), publiée en 1715 par Thomas Ilive, il s'insurgea ensuite avec vigueur contre le sabbataïsme que représentait à l'époque un certain Néhémie Hayyun, et qui prenait de l'ampleur à Londres ; il y implorait passionnément ses coreligionnaires de rester « in the holy and true faith and belief which we have received from our saintly and pious ancestors, and that we should refuse, abhor and detest the new gods and rituals which we do not know, nor our fathers ${ }^{92}$. Il édita encore un opuscule traitant du bain rituel, quatre volumes d'une concordance talmudique et une encyclopédie talmudique, Chaar DaN (Portique de DaN), inachevée. Il laissa enfin des «notes médicales » et une attaque virulente et circonstanciée contre l'Eglise catholique et l'Inquisition espagnole, Recondite Notice of the Inquisition of Spain and Portugal, qui parut en 1728, de façon posthume ${ }^{93}$. Il s'éteignit le 10 janvier 1728. Son fils Isaac composa plusieurs oraisons funèbres, les Sermones fúnebres a las deplorables memorias del muy Reverendo, y Doctísimo H. H. y Doctor R. David Nieto, sur 87 pages, et l'on peut lire sur sa tombe cette inscription, composée par Isaac de Sequeira :

Sublime theologian, profound sage, distinguished physician, famous astronomer, sweet poet, elegant preacher, subtle logician, ingenious physician, fluent rhetorician, pleasant author, expert in languages, learned in history ${ }^{94}$.

Le haham David Nieto vit-il les fruits de ses efforts incessants et inlassables en faveur de ses coreligionnaires? Quelques années supplémentaires s'avérèrent de fait nécessaires pour venir à bout des menaces contre lesquelles il avait lutté : Hayyun décéda en 1730, oublié; le sabbataïsme finit par disparaître, tout comme les Karaïtes et les Déistes, et l'Inquisition espagnole fut enfin abolie en 1834. La Loi Orale représenta certes la cible de maintes nouvelles attaques, mais elle incarne toujours le partenaire indissociable de la Bible. Remarquée et célébrée de son vivant, son œuvre littéraire a traversé les générations: réédité à de nombreuses reprises et notamment pour lutter contre la Réforme judéo-anglaise en 1842, étudié aujourd'hui encore dans certaines académies talmudiques en Israël et à travers le monde, Mateh DaN fait partie intégrante du corpus intellectuel du judaïsme orthodoxe. De longues années encore, les Juifs de Londres programmèrent l'entrée du shabbat en se référant aux horaires de Bina laitim, et la tradition des almanachs, qu'il avait amorcée en 1717, se perpétua dans la famille avec la parution du calendrier juif d'Abraham Nieto, à New York en 1902. David Nieto avait eu le bonheur de vivre à la tête de sa congrégation une période d'essor considérable, et la communauté séfarade de Londres prolongea son développement au cours du XVIII ${ }^{\mathrm{e}}$ siècle, enrichissant ses structures éducatives et élargissant ses installations caritatives, mais chérissant tout particulièrement et adoptant définitivement la synagogue de Bevis Marks qu'il avait inaugurée, et au sein de laquelle se vivent toujours les temps forts de son existence ${ }^{95}$. Elle connut assurément une période de déclin, mais elle se reporte aujourd'hui encore, empreinte d'une nostalgie mêlée de fierté sur l'ère de David Nieto son âge d'or. 
Figure 1 : La synagogue de Bevis Marks aujourd'hui. Carte postale.

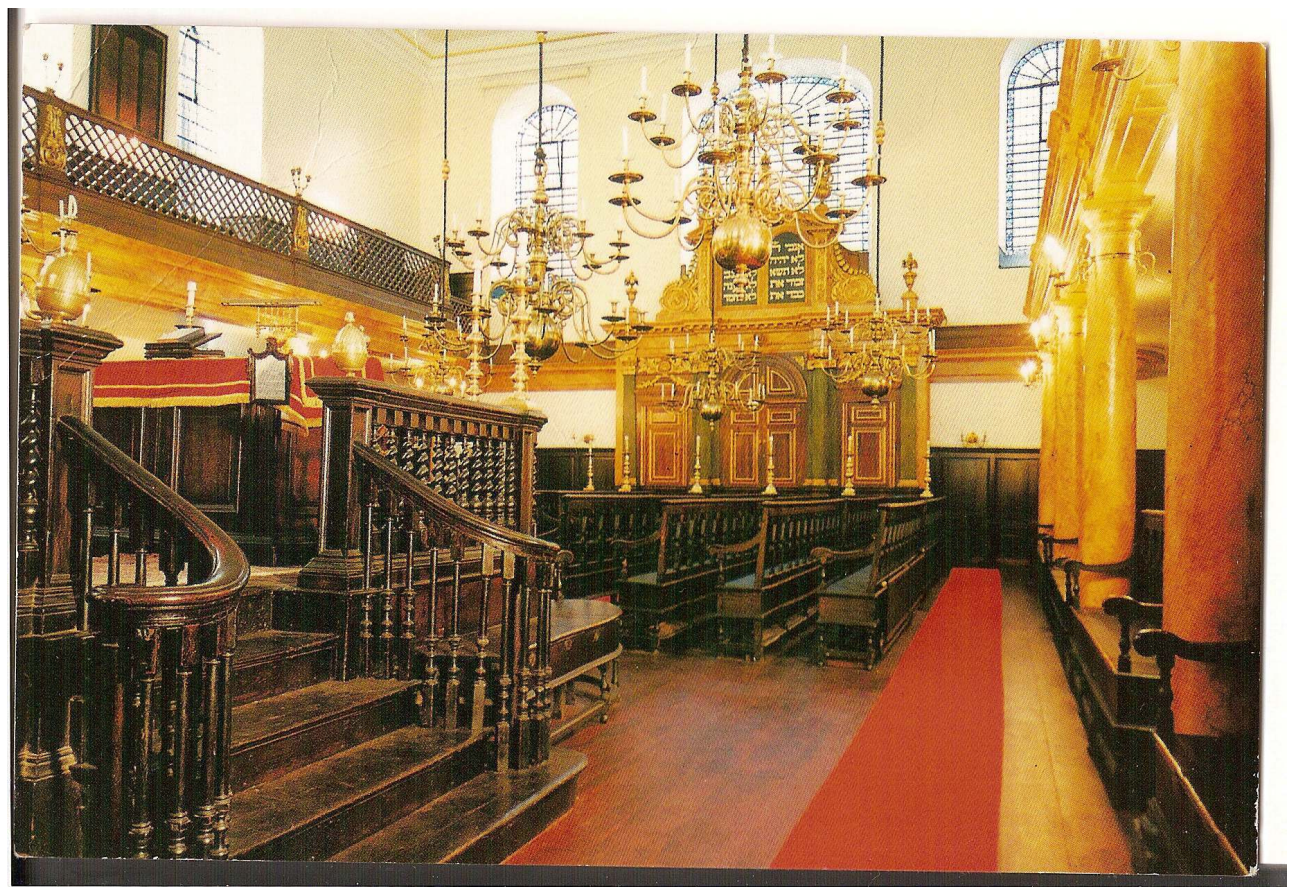

Figure 2 : Baron House ${ }^{96}$

\section{Malcolm Brown}

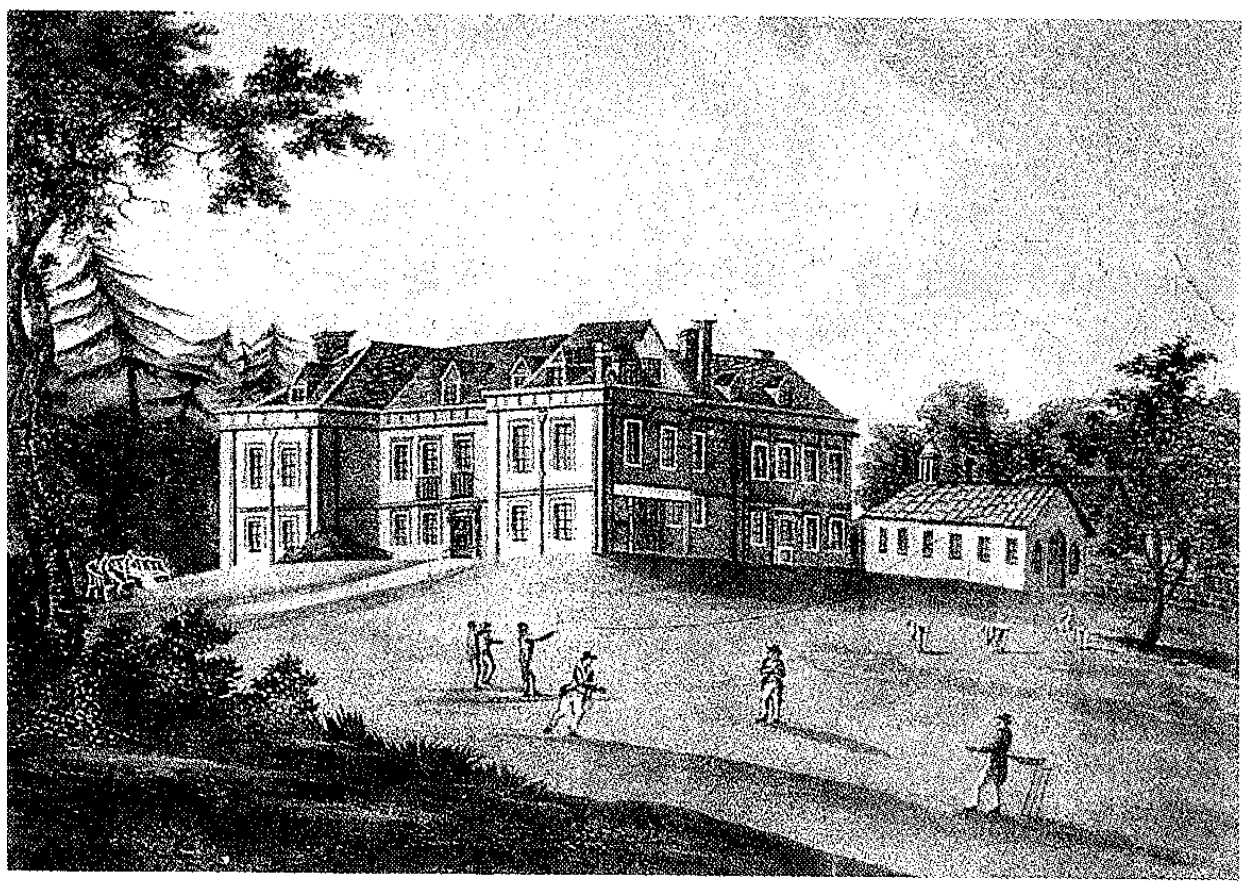


Figure 3 : Copped Hall97

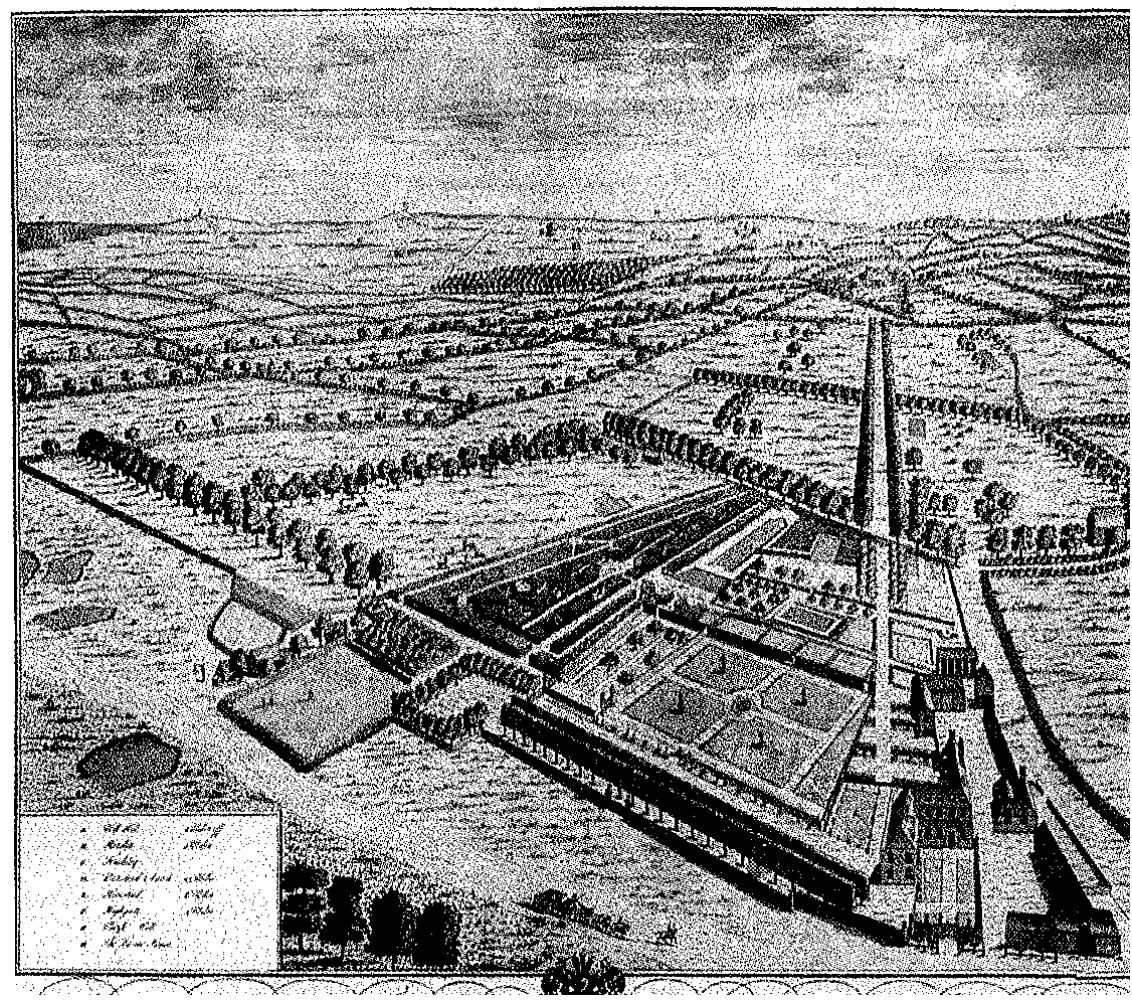

\section{BIBLIOGRAPHIE}

\section{Sources primaires :}

ABENDANA, Isaac. Discourses of the Ecclesiastical and Civil Polity of the Jews, London, 1706.

BARNETT, Lionel D. Bevis Marks Records; Contributions to the History of the Spanish and Portuguese Congregation of London. Volume I: The Early History of the Congregation from the Beginning until 1800, Oxford: O.U.P, 1940. Volume II: Abstracts of the Ketubot or Marriage-contracts of the Congregation from Earliest Times until 1837, Oxford: O.U.P, 1949.

BOYER, Abel. The History of the Reign of Queen Anne, Digested into Annals, London, 1712.

LOPES LAGUNA, Daniel Israël. Espejo fiel de vidas que contiene los psalmos de David en verso, London, $5480[1720]$.

MAITLAND, William. The History of London from its Foundation to the Present Time (2 vols.), London, 1769.

NIETO, David. Maté DaN (en hébreu) London, 1714 
SMITH, John. Chronicon rusticum-commerciale; or, memoirs of wool, \&c. Being a collection of history and argument, concerning the woolen manufacture and woolen trade in general, (2 vols.) London, 1747.

\section{Sources secondaires:}

BARNETT, Richard. "The Correspondence of the Mahamad of the Spanish and Portuguese Congregation of London during the Seventeenth and Eighteenth Centuries" Transactions of the Jewish Historical Society of England 20 (1964) 1-50.

BROWN, Malcolm. “Anglo-Jewish Country Houses from the Resettlement to 1800”, Transactions of the Jewish Historical Society of England 28 (1984) 20-25.

ENDELMAN, Todd. Radical Assimilation in English Jewish History: 1656-1945, Bloomington \& Indianapolis: Indiana University Press, 1990.

GASTER, Moses. History of the Ancient Synagogue of the Spanish and Portuguese Jews: the Cathedra Synagogue of the Jews in England situated in Bevis Marks. A Memorial Volume written Specially to Celebrate the Two-Hundredth Anniversary of its Inauguration 1701-1901, London, 1901.

GERMAIN, Lucienne. Réflexes identitaires et intégration : Les Juifs en Grande-Bretagne de 1830 à 1914, Paris : Honoré Champion, 2000.

HYAMSON, Albert M. The Sephardim of England, 1951; London: The Spanish and Portuguese Jews' Congregation, 1991.

LEVY-MIMRAN, Sarah-Anna. La Communauté juive à Londres au XVIII siècle, thèse de doctorat sous la direction de Suzy Halimi, soutenue le 6 janvier 2010 à la Sorbonne.

POLLINS, Harold. The Economic History of the Jews in England, London, Toronto: Fairleigh Dickinson University Press, 1982.

Rотн, Cecil. History of the Great Synagogue, London, 1690-1940, London: E. Goldston, 1950.

\section{NOTES}

1. Nous avons opté pour « Nieto ", la transcription espagnole, la plus courante, de son nom, dont la signification est « petit-fils » ou « descendant ». On trouve aussi la version portugaise, « Neto », employée par la famille et, parfois encore, « Netto » ou « Nietto ».

2. Derek TAYLOR, British Chief Rabbis 1664-2006, London: Valentine Mitchell, 2007, pp. 80-81.

3. Ce terme hébraïque renvoie sémantiquement à la sagesse et à la perspicacité (hokhma en hébreu) ; depuis l'expulsion des Juifs d'Espagne en 1492, haham est le titre du guide spirituel des communautés séfarades.

4. Certains historiens datent son arrivée à Londres en 1702. Israel solomons, "David Nieto and some of his Contemporaries", 1915 ; Transactions of the Jewish Historical Society of England 12 (1931), p. 8.

5. Moses GASTER, History of the Ancient Synagogue of the Spanish and Portuguese Jews: the Cathedra Synagogue of the Jews in England situated in Bevis Marks. A Memorial Volume written Specially to Celebrate the Two-Hundredth Anniversary of its Inauguration 1701-1901, London, 1901, p. 102.

6. Lucienne GERMAIN, Réflexes identitaires et intégration: Les Juifs en Grande-Bretagne de 1830 à 1914, Paris : Honoré Champion, 2000, p. 30.

7. Lionel D. BARNETT, Bevis Marks Records; Contributions to the History of the Spanish and Portuguese Congregation of London. Volume I: The Early History of the Congregation from the Beginning until 1800, 
Oxford: O.U.P, 1940. Volume II: Abstracts of the Ketubot or Marriage-contracts of the Congregation from Earliest Times until 1837, Oxford: O.U.P, 1949, pp. 22-23.

8. Derek TAYLOR, op. cit., p. 96.

9. Israel SOLOMONS, op. cit., p. 2.

10. Derek TAYLOR, op. cit., p. 85.

11. Une plaque commémorative marque aujourd'hui l'emplacement de cette première synagogue, dans Creechurch Lane, au cœur de la City.

12. Edgar SAMUEL, At the End of the Earth: Essays on the History of the Jews of England and Portugal, London: The Jewish Historical Society of England, 2004, pp. 192-193.

13. Derek TAYLOR, op. cit., p. 84.

14. Lionel D. BARNETT, op. cit., vol. 1, pp. 24-25.

15. Derek TAYLOR, op. cit., p. 84.

16. Voir la figure 1.

17. Albert M. HYAMSON, The Sephardim of England, 1951; London: The Spanish and Portuguese Jews'

Congregation, 1991, pp. 70-71.

18. Derek TAYLOR, op. cit., p. 83

19. Ibid., p. 91.

20. Ibid., p. 37.

21. Lucienne GERMAIN, op. cit., p. 31.

22. Cette restriction s'effaça en 1830 .

23. Albert M. HYAMSON, op. cit., pp. 89-90.

24. Cecil RоTH, History of the Great Synagogue, London, 1690-1940, London: E. Goldston, 1950, p. 66.

25. Sarah-Anna LEVY-MIMRAN, La Communauté juive à Londres au XVIII siècle, thèse de doctorat sous la direction de Suzy Halimi, soutenue le 6 janvier 2010 à la Sorbonne, pp. 127-128.

26. Albert M. HYAMSON, op. cit., p. 70.

27. Voir la figure 2.

28. Voir la figure 3. Malcolm BRown, "Anglo-Jewish Country Houses from the Resettlement to 1800", Transactions of the Jewish Historical Society of England 28 (1984), pp. 20-25.

29. Le terme que l'on rencontre le plus souvent dans les textes est celui de Marranes. Ce terme exprime cependant le mépris des Chrétiens qui les dénommèrent ainsi : marranos = cochons... Les Juifs les appelèrent les anoussim = convertis de force. Nous avons opté pour l'expression « CryptoJuifs " que l'on rencontre chez certains historiens, tels Edgar SAMUEL, David KATZ, et Gérard NAHON. Juifs convertis au catholicisme dans des circonstances tragiques, ces Crypto-Juifs continuaient de croire secrètement dans le Dieu d'Israël et d'observer en cachette les (ou une partie des) préceptes du judaïsme.

30. Le terme «marchand » est une appellation banalisée et assez généralisée à l'époque, ayant trait au commerce extérieur, mais renvoyant à un concept plutôt flou. Il arrive souvent que des personnes soient classées sous la rubrique «marchands » mais exercent d'autres activités, dans la finance ou le notariat, par exemple.

31. L'interdit d'importer des vêtements et tissus étrangers au Portugal s'imposa entre 1684 et 1703, date à laquelle le traité de Methuen ouvrit à nouveau la voie des importations et facilita notamment l'importation du vin portugais.

32. John SMITH, Chronicon rusticum-commerciale; or, memoirs of wool, \&c. Being a collection of history and argument, concerning the woolen manufacture and woolen trade in general, (2 vols.) London, 1747, vol 2, pp. 142-144.

33. Harold Pollins, The Economic History of the Jews in England, London, Toronto: Fairleigh Dickinson University Press, 1982, pp. 44-46.

34. En 1688 déjà, on comptait deux synagogues à la Barbade et une autre à la Jamaïque.

35. Edgar SAMUEL, op. cit., p. 370. 
36. Derek TAYLOR, op. cit., p. 34.

37. Ibid., p. 83.

38. Albert M. HYAMSON, op. cit., pp. 427-428.

39. Abel BOYER, The History of the Reign of Queen Anne, Digested into Annals, London, 1712, p. 75.

40. Genèse $26: 12$

41. Derek TAYLOR, op. cit., p. 82.

42. Entre 1679 et 1779, la communauté séfarade de Londres offrit annuellement au maire un don accompagné d'une plaque. Au départ garni de pâtisseries, le cadeau fut plus tard rehaussé de chocolats ou d'un don de $50 £$. Enfin, en 1780, alors que la communauté traversait une crise financière et alors qu'elle ne redoutait déjà plus la mauvaise volonté du maire à son égard, le don annuel cessa. Cf. Edgar SAMUEL, op. cit., pp. 377-379.

43. Harold POLLINS, op. cit., p. 58.

44. Rappelons que, dans la loi juive, une personne dépendant de la charité doit également contribuer à la charité : donner constitue une part essentielle de la dignité humaine.

45. Talmud de Babylone, Baba Bathra 10a : «Turnus Rufus interrogea Rabbi Akiva : «Si votre Dieu aime véritablement les pauvres, pourquoi ne s'occupe-t-Il pas de subvenir à leurs besoins?» Il répondit : « Afin de nous épargner à nous le châtiment divin, et afin de donner aux êtres humains l'occasion de multiplier les actes généreux ».

46. Cette pétition faisait suite à la proposition faite au Parlement d'imposer à la communauté juive de Londres une taxe de $100000 £$ par an - proposition qui se vit finalement refusée.

47. Edgar SAMUEL, op. cit., p. 369.

48. Richard BARNETT, "The Correspondence of the Mahamad of the Spanish and Portuguese Congregation of London during the Seventeenth and Eighteenth Centuries" in Transactions of the Jewish Historical Society of England 20 (1964) 1-50, p. 3.

49. Lionel D. BARNETT, op. cit., vol. 2, pp. 66-69 \& 73-84.

50. Richard BARNETT, op. cit., p. 4.

51. Israel SOLOMONS, op. cit., p. 25.

52. Cf. Neville LASKI, The Laws and Charities of the Spanish and Portuguese Jews' Congregation of London (1952). L'éducation des filles de familles pauvres fut prise en charge dès 1730, au sein de la Villareal School, fondée par Isaac Da Costa Villareal et dirigée par un comité de dames bénévoles qui leur consacraient de leur temps.

53. Richard BARNETT, op. cit., pp. 23-24.

54. Lionel D. BARNETT, op. cit., vol. 1, p. 26.

55. Richard BARNETT, op. cit., pp. 20-21.

56. Derek TAYLOR, op. cit., p. 96.

57. En 1432, le grand rabbin de Castille convoquait à Valladolid le congrès des Juifs de Castille pour énoncer les statuts régissant toutes les communautés juives castillanes. Les ascamot (statuts) furent composés en espagnol, mais transcrits en caractères hébraïques : la nécessité d'un fonds destiné à l'éducation des enfants y occupe la toute première place ; le Rav (chef spirituel) joue un rôle prépondérant, et le Ma'amad ha-Kahal (Conseil de la communauté) a la haute main sur l'administration. Le texte complet (ne manquent que quelques lignes d'introduction) se trouve en version anglaise sur le site: [http://www.fordham.edu/halsall/source/1432synod-castilejews.html] (25/5/2011).

58. Derek TAYLOR, op. cit., p. 84.

59. Psaumes $68: 6$

60. Israel SOLOMONS, op. cit., p. 9 .

61. William MAITLAND, The History of London from its Foundation to the Present Time (2 vols.), London, 1769, vol. 2, p. 1190.

62. Ibid., p. 1191. 
63. Isaac ABENDANA, Discourses of the Ecclesiastical and Civil Polity of the Jews, London, 1706, p. 127.

64. " Enseignement ", « répétition ", Mishna est le nom donné à la première compilation de la Loi Orale par le rabbin Juda Hanassi (vers 200), ainsi qu'à chaque paragraphe de cet ouvrage.

65. Israel SOLOMONS, op. cit., p. 21.

66. Ibid., p. 2-3.

67. Moses GASTER, op. cit., p. 105.

68. Cecil ROTH, op. cit., p. 72.

69. DaN est l'acronyme de son nom David Nieto.

70. Lionel D. BARNETT, op. cit., vol. 1, pp. 16-20.

71. Derek TAYLOR, op. cit., p. 83.

72. Cf. par exemple, Dissertatio in novam, tutam, ac utilem methodum inoculationis, seu transplantationis variolarum, London, 1722.

73. Cf. par exemple, A Dissertation on the Method of Inoculating the Small-Pox, London, 1722.

74. Sermam funebre as deploraveis memorias do muy Reverendo, e doutissimo Haham Asalem Morenu, A.R. David Netto, London, 1728.

75. Albert M. HYAMSON, op. cit., p. vi.

76. Moses GASTER, op. cit., pp. 1-2.

77. Les Juifs convertis d'Espagne et du Portugal étaient désignés comme Nouveaux-Chrétiens en France, en Espagne (cristianos nuevos) et au Portugal (cristâos novos).

78. Albert M. HYAMSON, op. cit., p. 33.

79. Todd ENDELman, Radical Assimilation in English Jewish History: 1656-1945, Bloomington \& Indianapolis : Indiana University Press, 1990, p. 24.

80. Israel SOLOMONS, op. cit., p. 24.

81. Psaumes $147: 8$

82. Philosophe hollandais, Baruch de Spinoza était issu d'une famille juive de commerçants, d'origine portugaise. Il fut exclu en 1656 de la communauté juive d'Amsterdam, en raison de ses idées religieuses non conformes à l'orthodoxie. Dans son ouvrage principal, l'Ethique (1677), il fait l'exposé le plus complet, sous une forme à la fois rationnelle et mystique, des doctrines panthéistes.

83. Israel SOLOMONS, op. cit., p. 13.

84. Ibid., p. 17.

85. John COVEL, professeur à Christ's College (Cambridge) conclut une lettre adressée à David Nieto en janvier 1706 à propos des calendriers, en notant qu'il embrasse également cette position : «Universal Nature seems to me not more or less than the Platonic Chimera, that is, the soul of the world, or a blind and vicarious Spirit, senseless, without reason, which, I do not know by what plastic virtue, leads the particular Nature of everything. How I laugh about these foolish things! From God alone proceeds every good thing [...]» (Solomons 24).

86. Les Néo-Karaïtes se caractérisaient par leur opposition à la Loi orale ou à la compréhension littérale de certains écrits rabbiniques.

87. Mouvement qui s'organisa à l'origine autour du faux-messie Sabbatai Tzevi (1626-1676) et qui eut au cours du XVIII ${ }^{e}$ siècle de grandes répercussions sur certaines croyances juives et, notamment, sur le messianisme.

88. David NIETO, Maté Dan- Kouzari chéni, introduction (je traduis de l'hébreu), 2.

89. Sous une forme identique, le Kouzari avait pris en son temps la défense de la Loi écrite (la Bible) alors que la communauté juive espagnole se laissait tenter, tantôt au Nord par le christianisme, tantôt au Sud, par l'Islam. Notons d'ailleurs que le haham David Nieto a donné un second titre à son œuvre Maté DaN : Kouzari chéni (second Kouzari).

90. David NIETo,. Maté DaN (en hébreu) London, 1714, pp 6-8.

91. Derek TAYLOR, op. cit., p. 95.

Revue Française de Civilisation Britannique, XVII-2 | 2012 
92. Israel SOLOMONS, op. cit., p. 33.

93. Derek TAYLOR, op. cit., p. 96.

94. Richard BARNETT, op. cit., p. 15.

95. Voir le site de la synagogue : http://www.bevismarks.org.uk.

96. Malcolm BRown, op. cit., p. 24

97. Ibid.., p. 24

\section{RÉSUMÉS}

Après avoir fui les persécutions de l'Inquisition et échappé à sa redoutable traque, les Juifs séfarades trouvent à Londres un havre de relative tolérance et la promesse de nouvelles espérances. Ils s'organisent activement et, en 1701, la congrégation inaugure l'admirable synagogue de Bevis Marks et intronise David Nieto, auquel elle confie la présidence de sa destinée spirituelle. Sous l'influence de cet homme d'envergure aux compétences multiples, une période d'essor - que d'aucuns qualifient d'âge d'or - est amorcée, la croissance rayonnant sur la solidarité, l'action caritative et l'éducation. Les défis restent toutefois nombreux et le rabbin est notamment confronté au dossier brûlant de l'identité spirituelle de cette minorité juive à la «préhistoire » troublante : les fidèles sont en effet issus pour la plupart de familles crypto-juives ayant adopté la religion catholique en temps de turbulences, sans se défaire d'une appartenance au judaïsme de laquelle ils se réclamaient en secret.

After they fled the persecutions of the Inquisition and escaped its awesome chase, the Sephardic Jews found in London a haven of relative tolerance and the promise of new prospects. They actively organised themselves and, in 1701, the community inaugurated the admirable Bevis Marks Synagogue and installed David Nieto in his post of rabbi of the congregation. Under the influence of this multi-skilled and brilliant spiritual guide, a period of development -which some describe as a Golden Age- began, its social and economic growth including solidarity, charity and education. Yet the challenges remained numerous and the rabbi was mainly confronted with the burning issue of this particular Jewish minority's spiritual identity: the members of the community actually brought with them an unsettling "prehistory" since they mostly came from Crypto-Jewish families, who had adopted the Catholic religion in times of difficulties, without however getting rid of their membership to Judaism -which they had permanently practised in secret.

\section{AUTEUR}

\section{SARAH MIMRAN}

Sarah-A. Mimran, diplômée du Jewish Teachers' Training College (Gateshead, R.U), titulaire d'une maîtrise d'hébreu moderne (INALCO) et d'un doctorat d'anglais (Sorbonne Nouvelle-Paris 3), enseigne la littérature biblique, l'histoire et la pensée juives dans le privé. Sa thèse, soutenue en janvier 2010, portait sur la communauté juive à Londres au XVIII ${ }^{e}$ siècle. Son champ de recherche couvre l'histoire juive en général, et plus particulièrement l'Anglo-judaïsme, de la réadmission (1656) à l'époque contemporaine. 